\title{
NÚCLEOS DE APOIO À SAÚDE DA FAMÍLIA: CONCEPÇÕES, IMPLICAÇÕES E DESAFIOS PARA O APOIO MATRICIAL
}

\author{
FAMILY HEALTH SUPPORT CENTERS: CONCEPTIONS, IMPLICATIONS \\ AND CHALLENGES FOR THE MATRIX SUPPORT
}

\author{
NÚCLEOS DE APOYO A LA SALUD DE LA FAMILIA: CONCEPCIONES, \\ IMPLICACIONES Y DESAFÍOS PARA EL APOYO MATRICIAL
}

\author{
José Patrício Bispo Júnior ${ }^{1}$ \\ Diane Costa Moreira ${ }^{2}$
}

Resumo O estudo objetivou analisar o sentido atribuído ao trabalho dos Núcleos de Apoio à Saúde da Família, assim como analisar os entraves e desafios para a prática cotidiana do apoio matricial. É um estudo qualitativo do tipo casos múltiplos, desenvolvido em seis municípios da Bahia. Foram realizadas entrevistas semiestruturadas com 43 profissionais dos núcleos de apoio e 40 das equipes de saúde da família. Utilizou-se o referencial teórico do apoio matricial nas dimensões pedagógica, terapêutica e institucional. Os resultados foram agrupados em três categorias: (in)compreensões sobre o trabalho dos núcleos de apoio; infraestrutura e condições de trabalho; valorização e gestão do trabalho. $\mathrm{O}$ estudo revelou existir compreensões divergentes entre os apoiadores e as equipes de saúde da família sobre a função do matriciamento, com expectativas conflitantes e implicações para o trabalho. A infraestrutura existente mostrou-se insuficiente e inadequada para o trabalho do apoio matricial. A baixa valorização dos núcleos de apoio também foi evidenciada por meio da diminuta adesão da comunidade às atividades coletivas, da remuneração insatisfatória e da sobrecarga de trabalho. Incompreensões sobre o caráter inovador do matriciamento e dificuldades estruturais apontam desafios ainda persistentes para a concretização da função de apoio. Palavras-chave atenção primária à saúde; saúde da família; equipe de assistência ao paciente; pessoal de saúde.
Abstract This study intended to analyze the assigned meaning and the contributions of the work of the Family Health Support Centers, as well as the barriers and challenges to the daily practice of matrix support. This is a qualitative study involving multiple cases, which was performed in six cities in Bahia, Brazil. Semi-structured interviews were conducted with 43 professionals from the support centers and 40 from the family health teams. We used the theoretical reference of the matrix support in the pedagogical, therapeutic and institutional dimensions. The results were grouped into three categories: (Mis) Understandings about the work of the support centers; Infrastructure and working conditions; Appreciation and management of work. Our study has unveiled divergent understandings among supporters and family health teams about the role of the matrix support process, with conflicting expectations and implications for work. The current infrastructure has proved to be insufficient and inappropriate for the work of matrix support. The little appreciation of the support centers was also highlighted through the low adherence of the community to the collective activities, unsatisfactory wages and excessive workload. Misunderstandings about the innovative nature of matrix support and structural difficulties indicate outstanding challenges for achieving the supportive function. Keywords primary health care; family health; patient care team; helath personnel. 


\section{Introdução}

A atenção primária à saúde (APS) pode assumir várias conformações a depender das características dos sistemas de saúde e dos interesses e ideologias que predominam em cada país (Abiiro e De Allegri, 2015). Entre os diferentes modelos, a APS pode se constituir como pacote básico de serviços destinado à população de baixo poder aquisitivo ou como mecanismo estruturante do sistema de saúde, fundamentado nos princípios do cuidado integral e da saúde como direito social (Giovanella e Medonça, 2012). De acordo com Starfield (2012), são cada vez mais consistentes as evidências, tanto nos países industrializados como nos em desenvolvimento, de que a APS abrangente, organizada por sistemas públicos universais, possibilita maior acesso e maior disponibilidade dos serviços de saúde necessários, mais eficientes e equânimes.

No Brasil, a APS é desenvolvida com base na compreensão ampliada de saúde. Organiza-se por ações no âmbito individual e coletivo com atuação na promoção, prevenção, diagnóstico, tratamento e reabilitação. Busca prestar atenção integral com respeito à autonomia do sujeito e a sua inserção sociocultural. Dentre outras diretrizes, visa possibilitar o acesso universal e contínuo a serviços de saúde de qualidade e resolutivos (Brasil, 2012).

A Estratégia Saúde da Família (ESF) é a forma prioritária para organização da APS no país. A reorientação do processo de trabalho, com aprofundamento dos vínculos e longitudinalidade do cuidado, figura entre as diretrizes da estratégia (Giovanella e Medonça, 2012). Com o propósito de ampliar o escopo e a resolutividade da ESF, foram criados os Núcleos de Apoio à Saúde da Família (NASF). Estes núcleos são compostos por profissionais de diferentes formações ou especialidades e devem atuar de maneira integrada às equipes Saúde da Família (eSFs), no intuito de auxiliar no manejo e resolução de problemas clínicos e sanitários (Brasil, 2014). Diante de necessidades de saúde cada vez mais complexas, os núcleos de apoio constituem-se em mecanismo de grande potência por agregar diferentes saberes e propor novas ferramentas de gestão do cuidado na APS.

O trabalho do NASF é orientado pelo referencial teórico-metodológico do apoio matricial (Brasil, 2014). Esse arranjo envolve uma equipe de referência, que é responsável pela gestão do cuidado, e uma equipe de apoio, que presta suporte técnico pedagógico e retaguarda especializada (Campos et al., 2014). As ações de apoio vão desde as esferas de promoção da saúde e de prevenção de agravos até ações clínico-assistenciais.

$\mathrm{O}$ apoio matricial tem como base a metodologia Paideia que prevê mudanças nas relações de poder, por meio de mecanismos de cogestão e do desenvolvimento da capacidade de tomar decisões, lidar com conflitos e estabelecer diálogo (Oliveira e Campos, 2015). Assim, o matriciamento objetiva superar as metodologias tradicionais de trabalho e de gestão. É capaz de assegurar retaguarda especializada às equipes de referência, com personalização e in- 
teratividade que envolve todos os atores, inclusive os usuários, nas ações desenvolvidas. Além disso, fornece suporte técnico-pedagógico às equipes apoiadas (Cunha e Campos, 2011).

A ferramenta do apoio matricial opera em direção à construção compartilhada do cuidado e visa promover a cogestão e democratização das relações nas instituições, com aumento da capacidade resolutiva das equipes de referência, o que as qualifica para a atenção ampliada à saúde. Desta forma, objetiva superar os modelos verticalizados de referência e contrarreferência, com o desenvolvimento de mecanismos horizontalizados de compartilhamento de saberes e de organização dos fluxos na rede de atenção (Oliveira e Campos, 2015; Cunha e Campos, 2011).

$\mathrm{O}$ trabalho do NASF é direcionado a dois públicos-alvo, as equipes apoiadas e os usuários, mas mesmo para estes, o acesso deve ser mediado ou demandado de acordo com as necessidades das eSFs. Neste sentido, a atuação dos núcleos tem como base o multiprofissionalismo e a interdisciplinaridade e tem como proposta o estabelecimento do projeto terapêutico compartilhado, construído e pactuado entre todos os envolvidos na produção do cuidado. As diretrizes ministeriais (Brasil, 2014) apresentam como ferramentas do trabalho: o Projeto Terapêutico Singular (PTS), o trabalho com grupos, o Projeto Saúde no Território (PST), a interconsulta, a visita domiciliar, o atendimento individual específico e a elaboração de materiais educativos.

O processo de trabalho fundamentado no apoio matricial destoa dos formatos tradicionais do fazer em saúde e, portanto, apresenta desafios para a prática cotidiana das eSFs e para o próprio NASF. Estudos demonstram que a relação entre os profissionais das duas equipes muitas vezes apresenta discrepâncias na atuação, uma vez que há um desentendimento sobre qual é a função da equipe de apoio, além das diferenças existentes entre as lógicas de trabalho, produtividades e exigências dadas a ambas (Anjos et al., 2013; Gonçalves, et al., 2015; Lancman, et al., 2013; Martinez, Silva e Silva 2016). As disparidades entre o trabalhar das equipes podem inviabilizar o diálogo entre elas, de forma a produzir um fazer em saúde individualizado, fragmentado, quando não concorrentes entre si.

Assim, o adequado entendimento sobre o apoio matricial, o processo de trabalho do NASF e as contribuições que pode agregar à APS são fatores com forte poder de influência na organização do trabalho. Desta forma, esse estudo tem como objetivo analisar o sentido atribuído ao trabalho do NASF pelos profissionais das equipes de referência e de apoio, assim como analisar os entraves e desafios para a prática cotidiana do apoio matricial.

\section{Abordagem metodológica}

Trata-se de uma pesquisa de abordagem qualitativa, do tipo casos múltiplos (Yin, 2010). Os sujeitos que compuseram o estudo foram profissionais do NASF e de nível superior das eSFs de seis municípios da área de abrangência do Núcleo Regional de Saúde do Sudoeste da Bahia: Vitória da Conquista, 
Poções, Barra do Choça, Guanambi, Brumado e Belo Campo. Para os profissionais das eSFs, optou-se por contemplar apenas enfermeiros e médicos, por serem os de maior contato com os núcleos de apoio. Os critérios de inclusão dos municípios foram ter NASF do tipo I há pelo menos um ano e ter obtido o assentimento da gestão municipal para a realização do estudo. A Tabela 1 caracteriza os municípios e equipes estudadas. As populações destas cidades variaram entre 18.383 a 343.230 habitantes.

\section{Tabela 1}

Caracterização dos municípios e das equipes estudadas. Municípios participantes da pesquisa, Bahia, 2015

\begin{tabular}{|c|c|c|c|c|}
\hline Município & $\begin{array}{l}\text { População } \\
\text { (2015) }\end{array}$ & $\begin{array}{c}\text { Número de } \\
\text { NASF existentes }\end{array}$ & $\begin{array}{c}\text { Número de } \\
\text { profissionais do NASF } \\
\text { entrevistados }\end{array}$ & $\begin{array}{l}\text { Número de } \\
\text { profissionais das } \\
\text { eSF entrevistados }\end{array}$ \\
\hline Município A & 38.853 & 1 & $\begin{array}{l}1 \text { Prof. Educação Física } \\
1 \text { Nutricionista } \\
1 \text { Psicólogo } \\
2 \text { Fisioterapeuta }\end{array}$ & $\begin{array}{l}4 \text { Enfermeiros } \\
2 \text { Médicos }\end{array}$ \\
\hline Município B & 18.383 & 1 & $\begin{array}{l}1 \text { Fisioterapeuta } \\
2 \text { Psicólogos } \\
1 \text { Enfermeira sanitarista } \\
1 \text { Assistente social } \\
2 \text { Nutricionista }\end{array}$ & $\begin{array}{l}1 \text { Enfermeiro } \\
2 \text { Médicos }\end{array}$ \\
\hline Município C & 69.255 & 3 & $\begin{array}{l}1 \text { Assistente Social } \\
1 \text { Nutricionista } \\
1 \text { Farmacêutico } \\
1 \text { Fisioterapeuta }\end{array}$ & $\begin{array}{l}6 \text { Enfermeiros } \\
2 \text { Médicos }\end{array}$ \\
\hline Município D & 85.797 & 2 & $\begin{array}{l}1 \text { Farmacêutico } \\
1 \text { Nutricionista } \\
2 \text { Assistente Social } \\
2 \text { Prof. Educ. Física } \\
\text { Fisioterapeuta }\end{array}$ & $\begin{array}{l}5 \text { Enfermeiros } \\
1 \text { Médico }\end{array}$ \\
\hline Município E & 48.729 & 2 & $\begin{array}{l}1 \text { Psicólogo } \\
1 \text { Assistente Social } \\
2 \text { Prof. Educ. Física } \\
2 \text { Nutricionista } \\
2 \text { Fisioterapeuta }\end{array}$ & 5 Enfermeiros \\
\hline Município F & 343.230 & 4 & $\begin{array}{l}1 \text { Prof. Educação Física } \\
2 \text { Nutricionista } \\
2 \text { Farmacêutico } \\
2 \text { Psicólogo } \\
3 \text { Fisioterapeuta }\end{array}$ & $\begin{array}{l}6 \text { Enfermeiros } \\
6 \text { Médicos }\end{array}$ \\
\hline Total de entr & & & 43 NASF & 40 eSFs \\
\hline
\end{tabular}

Fonte: População - IBGE (Brasil, 2016); Número de NASF e profissionais entrevistados - dados da pesquisa.

Notas: NASF - Núcleos de Apoio à Saúde da Família; eSF - equipe Saúde da Família. 
Com base nos constructos e proposições de Campos e colaboradores (2014), Oliveira e Campos (2015) e Cunha e Campos (2011), adotou-se nesse estudo o referencial teórico do apoio matricial, principal fundamento de organização do trabalho do NASF. O apoio matricial é uma metodologia de trabalho que congrega um conjunto de conceitos e lógica organizativa de como fazer o trabalho interprofissional. De acordo com Campos et al. (2014), a metodologia de apoio busca produzir, simultaneamente, efeitos nas dimensões pedagógicas, terapêuticas e institucionais. O Quadro 1 sintetiza os principais efeitos esperados da utilização do apoio matricial entre equipes de saúde. Importante considerar que essas dimensões estão interrelacionadas e afetam-se mutuamente (Figura 1).

\section{Quadro 1}

Caracterização dos municípios e das equipes estudadas. Municípios participantes da pesquisa, Bahia, 2015

\begin{tabular}{|c|c|c|}
\hline dagógica & Dimensão terapêutica & Dimensão institucional \\
\hline $\begin{array}{l}\text {-Aprimoramento do repertório } \\
\text { de conhecimentos, dos modos } \\
\text { de compreender e de fazer e dos } \\
\text { profissionais. } \\
\text {-Busca do apoio de outras áreas para } \\
\text { fortalecer a atuação e cumprir suas } \\
\text { tarefas. } \\
\text { - Ações realizadas conjuntamente e } \\
\text { apoio técnico-pedagógico entre as } \\
\text { equipes como mecanismo de formação } \\
\text { e educação permanente. }\end{array}$ & $\begin{array}{l}\text { - Superação da ideia de responsabilidade } \\
\text { por atividades (grupais ou individuais) } \\
\text { ou procedimentos e aprimoramento } \\
\text { da responsabilidade de pessoas } \\
\text { por pessoas. } \\
\text { - Pactuação de estratégias e ações para } \\
\text { atuação frente a casos difíceis com o } \\
\text { intuito de ampliar a resolutividade } \\
\text { da atenção. } \\
\text {-Ampliação das práticas clínicas } \\
\text { para além dos riscos biológicos, com } \\
\text { consideração da subjetividade e dos } \\
\text { determinantes sociais e políticos. }\end{array}$ & $\begin{array}{l}\text {-Constituição de novos arranjos } \\
\text { organizacionais que visem superar } \\
\text { a lógica fragmentada da referência } \\
\text { e contrarreferência e promover } \\
\text { mecanismos de integração dialógica } \\
\text { entre as especialidades e profissões. } \\
\text { - Desenvolvimento da cogestão nas } \\
\text { relações interprofissionais e superação } \\
\text { das relações assimétricas de poder } \\
\text { entre profissões e equipes. } \\
\text { - Pactuação entre as equipes e os } \\
\text { gestores municipais de novas formas } \\
\text { de organização do trabalho na atenção } \\
\text { primária, com viabilização das condições } \\
\text { de trabalho para o desenvolvimento } \\
\text { dos mecanismos de apoio }\end{array}$ \\
\hline
\end{tabular}

Fonte: Sintetizado a partir da proposta de apoio matricial de Campos e colaboradores (2014), Oliveira e Campos (2015) e Cunha e Campos (2011). 
Dinâmica do apoio matricial com as dimensões pedagógica, terapêutica e institucional.

\section{Dimensăo pedagogica}

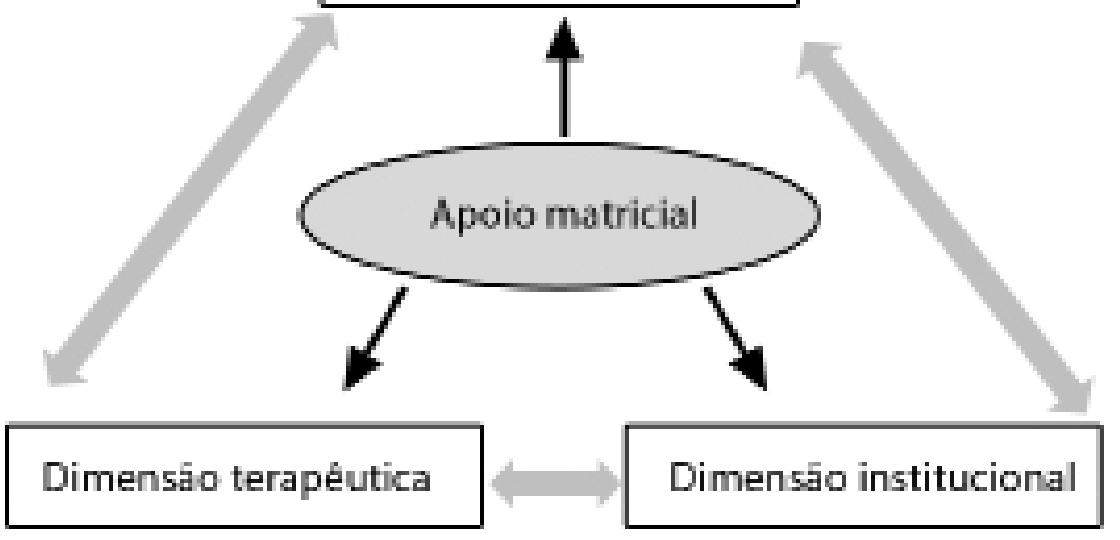

Fonte: Elaborada pelos autores com na base proposta de apoio matricial de Campos e colaboradores (2014); Oliveira e Campos (2015); e Cunha e Campos (2011)

Os profissionais que participaram da pesquisa deveriam ter atuação superior a seis meses na eSFs e na equipe de apoio, a fim de garantir a existência de entrosamento entre os pesquisados, e conhecimento acerca dos objetivos que se pretendeu analisar. Os sujeitos que atendiam ao critério descrito foram contatados pessoalmente e convidados a fazer parte do estudo. O período do estudo foi de junho de 2014 a fevereiro de 2015. O total de participantes foram 43 do NASF e 40 da eSF (Tabela 1).

As informações foram obtidas por meio de entrevistas semiestuturadas, gravadas em aparelho de áudio digital. Utilizou-se um roteiro para as eSFs (enfermeiro e médico) e outro para as equipes de apoio, adaptados de acordo com a especificidade de cada grupo. As entrevistas foram realizadas pelos autores deste artigo e por outros dois pesquisadores treinados. Elas tiveram duração média de 40 minutos, com 56 horas e 12 minutos de tempo de gravação total. Durante as entrevistas foram abordadas questões referentes à compreensão, significado e contribuições do trabalho do NASF, à infraestrutura e condições de trabalho e à valorização e gestão do trabalho. As entrevistas foram transcritas e validadas entres os membros da equipe de pesquisa.

A etapa analítica foi desenvolvida com o uso da a técnica de análise de conteúdo temática, com codificação e identificação das unidades de sentido. As falas foram ordenadas e classificadas por meio da leitura exaustiva, na qual se observaram a estrutura e os sentidos das mesmas. Assim, estabeleceu-se um código para todas as falas que apresentavam a mesma ideia ou conteúdo semelhante. Desta forma, as categorias e subcategorias emergiram da mediante a interconexão de temas que mais se aproximavam uns dos outros (Gibbs, 2009). 
Observaram-se todos os requisitos éticos preconizados pela resolução CNS n. 466/2012 e garantiu-se o anonimato dos participantes. As entrevistas só foram realizadas após autorização e assinatura do termo de consentimento livre e esclarecido. A pesquisa foi aprovada pelo Comitê de Ética e Pesquisa do Instituto Multidisciplinar em Saúde da Universidade Federal da Bahia (IMS-UFBA), de acordo com o parecer n. 377.448/2013. O estudo contou com o apoio financeiro do Programa de Pesquisa para o SUS: Gestão Compartilhada em Saúde (PPSUS), por meio do edital n. 20/2013, da Fundação de Amparo à Pesquisa do Estado da Bahia (Fapesb).

Mediante a análise do corpus, os resultados obtidos foram organizados em três categorias: (In)compreensões sobre o trabalho do NASF; infraestrutura e condições de trabalho; e valorização e gestão do trabalho. A seguir são apresentados e discutidos os achados das respectivas categorias.

\section{(In)compreensões sobre o trabalho do NASF}

Os resultados evidenciaram existir polaridade sobre a compreensão do trabalho dos núcleos de apoio, com o desencadeamento de expectativas frustradas e interferências na articulação entre equipes. As compreensões díspares concentraram-se, de um lado, no entendimento de que o trabalho do NASF deve direcionar-se quase que exclusivamente a atividades coletivas, e, do outro, que a ação desses núcleos deveria ter foco na assistência curativa e individualizada. Observou-se que a polarização no entendimento se dividia entre os dois tipos de equipes. Entre os profissionais das equipes de apoio predominou a concepção de que o trabalho deve ser desenvolvido por meio de atividades coletivas e de cunho educativo. Em alguns casos, observou-se a negativa da possibilidade atendimento individual.

Na verdade, o NASF trabalha mais na lógica da promoção e prevenção da saúde, né? De levar orientação pro usuário. Aqui como a gente não faz atendimento específico, né? Pra educação, mas, voltado pra promoção e prevenção do ambiente, né? Da saúde (NASF 23, Prof. Educação Física).

Por sua vez, entre as eSFs predominou a compreensão de que o trabalho do NASF deveria ser voltado para o atendimento clínico individualizado no âmbito da saúde da família. Observou-se o desejo e a expectativa de que os núcleos de apoio realizassem de maneira preponderante atendimentos especializados no auxílio à cura e à reabilitação dos usuários.

Eu vejo o papel do NASF como um papel de apoiador das Equipes de Saúde da

Família. (...) podendo transformar esse atendimento que a gente faz aqui, que é um atendimento prioritariamente clínico, né? Em um atendimento de certa 
forma especializado. Porque, como a gente tem cinco especialidades no NASF, que é a psicologia, educação física, fisioterapia, farmácia e nutrição. Isso. Então, muitas vezes, eu preciso desses complementos nessas consultas especializadas (eSFs 35, Médico).

A dualidade de concepções interfere nas práticas e condutas de cada um dos grupos, com dificuldades no desenvolvimento do trabalho conjunto e fragilidades na atuação do apoio matricial. Em consonância com tais achados, Barros et al. (2015) também identificaram que a lógica do apoio matricial ainda não está totalmente assimilada pelos profissionais das eSFs, o que dificulta a introdução deste formato de trabalho. Os autores identificaram que existem muitos desafios para que a prática do apoio matricial se efetive. Dentre estes, destacaram aspectos objetivos, como as diferenças de organização de trabalho entre as equipes, e aspectos subjetivos, relacionados à forma como os trabalhadores conseguiam expor ou não as suas necessidades, sem se sentirem frágeis diante dos colegas.

Com base no referencial adotado, o cenário revela fragilidades na dimensão pedagógica. A lógica de organização do trabalho com base no apoio matricial pouco foi compreendida por ambas as equipes. Nesse sentido, a implantação das equipes de apoio nos municípios estudados não desencadeou os efeitos esperados de transformação dos modos cotidianos de fazer dos profissionais e de ampliação dos processos educativos orientados pelo trabalho. O que também é um indicativo de fragilidade na dimensão institucional, visto que a presença do NASF não foi acompanhada de mudanças na organização do trabalho ou desenvolvimento de novas formas de gestão das relações interprofissionais.

A adequada compreensão sobre a ferramenta do apoio matricial é elemento essencial para ampliar a resolutividade na APS. O NASF trabalha numa lógica diferenciada do modelo hegemônico de fazer saúde, na qual prestar apoio significa trabalhar com matriciamento, com educação em saúde, com educação permanente, significa trabalhar no território, fortalecer a rede, além de prestar a retaguarda especializada às equipes apoiadas. Pressupõe, desta forma, o suporte técnico pedagógico, com atuação conjunta com a equipe de referência por meio de atividades educativas, ao mesmo tempo em que realiza ações específicas de cuidado (Campos et al., 2014; Brasil, 2014).

Assim, compreensões distorcidas, por ambas as equipes, sobre o que é e como se desenvolve o apoio matricial traz implicações e expectativas conflitantes para o trabalho. Os resultados do estudo demonstram que os profissionais dos núcleos não se sentem apoiados pela eSFs nas atividades coletivas e grupais, por sua vez as eSFs não se percebem apoiadas na retaguarda especializada. Ao analisar tais concepções, é possível inferir sobre a inadequabilidade e limitação dos dois polos observados. 
De acordo com os documentos norteadores do NASF, a este compete uma série de atribuições que concernem tanto aos aspectos promocional e preventivo como à atuação clínico-individualizada (Brasil, 2012; Brasil, 2014). Assim, destaca-se a necessidade de superação da visão fragmentada pelos profissionais de ambas as equipes. Os profissionais do NASF precisam estar mais abertos para as demandas assistenciais das comunidades e compreender a atribuição de apoio especializado nesse contexto. Da mesma forma, convém às eSFs entender que o NASF não pode se voltar apenas para as atividades curativas e reabilitadoras, mostrando-se necessário também maior empenho no apoio e articulação com os apoiadores para o desenvolvimento das atividades coletivas.

Sobre as contribuições para ampliar a resolutividade da APS, também se observaram compreensões dicotômicas entre os dois tipos de equipe. Os profissionais apoiadores enfatizaram que o seu trabalho impacta na melhoria da qualidade de vida da comunidade, percebida por meio das atividades de educação em saúde, na prevenção de doenças e na mudança de hábitos de vida. Além disso, foi destacada a ampliação de ações disponíveis para a comunidade, como grupos terapêuticos e visitas domiciliares.

O NASF contribui para a resolutividade da Saúde da Família através dos atendimentos compartilhados, das visitas domiciliares, dos grupos terapêuticos, da educação permanente, né? (NASF 03, Psicólogo).

Em contradição às potenciais contribuições destacadas, entre às eSFs predominou a compreensão que os núcleos pouco colaboram para que se percebam melhorias na saúde da comunidade. É referida uma baixa efetividade das ações, uma vez que não possui foco no atendimento às necessidades clínicas demandadas pela equipe e, assim, pouco contribuem para resolução dos problemas de saúde das comunidades. O imaginário identificado é o de que o NASF poderia ser bem mais resolutivo se pudesse exercer de forma especializada as funções de seus núcleos específicos de formação.

O NASF, ele passa a maior parte do tempo dele inativo, improdutivo. E, às vezes, o município não tem como arcar com o tanto de profissionais. E esses profissionais que ficam disponíveis, eles não podem atuar de forma mais complementar, entendeu? Ficam mais subjetivos [sic] a alguns criteriozinhos que eles têm que tá se submetendo. E não podem avançar no desenvolvimento dessas atividades de consulta que a gente precisa (eSF 14, Enfermeiro).

Nesse contexto, cabe refletir que o trabalho dos núcleos de apoio é voltado para as necessidades da população frente às demandas das eSFs e depende destas para se efetivar. Em situações em que a equipe não compreende e, em consequência, não contribui para o trabalho do NASF, não há como os profis- 
sionais de apoio desenvolverem o seu trabalho da maneira esperada. Assim, a inefetividade referida pode ser em grande parte influenciada pela própria postura de resistência das equipes apoiadas.

Em situação análoga, Lancman et al. (2013) identificaram que incompreensões e resistências desencadeiam nos próprios apoiadores sentimentos de impotência e subutilização. Os autores verificaram que os trabalhadores do NASF vivenciam falta de lugar na organização e sentimento de não pertencimento motivado pela invisibilidade frente às eSFs. Oliveira e Campos (2015) destacam as inciativas no cenário nacional e internacional para a participação conjunta de profissionais da atenção primária e especialistas no cuidado compartilhado, e para o desenvolvimento de projeto terapêutico em comum, o que visa superar a fragmentação da atenção.

As experiências internacionais demonstram a complexidade do trabalho articulado entre profissionais de diferentes núcleos de saber e apontam a interferência de dimensões pessoais, organizacionais e sistêmicas (D'Amour et al., 2008). Em estudos sobre o trabalho colaborativo e cuidado compartilhado no Canadá (D'Amour et al., 2008), Austrália (Schadewaldt et al., 2016) e Portugal (Souza et al., 2013) foram identificadas a influência do respeito mútuo, da clara compreensão sobre os papeis a serem desenvolvidos por cada profissional e da importância de existirem objetivos comuns decididos coletivamente.

No contexto brasileiro, a dificuldade de se trabalhar ações curativas e reabilitadoras conjuntamente com as ações de promoção e prevenção é ainda marcante e leva os profissionais e gestores a construírem um imaginário de que estes polos não podem se fazer de forma concomitante e articulada. Compreensões dessa natureza evidenciam também fragilidades na dimensão terapêutica e contribuem, em grande medida, como entrave para o desenvolvimento do apoio matricial, do trabalho do NASF e da resolutividade na APS (Sousa, Oliveira e Costa, 2015; Ribeiro e FloresSoares, 2015).

\section{Infraestrutura e condições de trabalho}

As questões estruturais foram também analisadas no estudo e constituíram-se ainda em desafio para o trabalho do NASF, assim como para as eSFs. Emergiram três subcategorias relacionadas à infraestrutura para o trabalho: espaço físico; transporte; e equipamentos e materiais.

Foram evidenciadas deficiências e inadequações dos espaços físicos para o trabalho do NASF. A estrutura das Unidades de Saúde da Família (USF) mostrouse insuficiente para a agregação dos novos profissionais a esses espaços, com 
quantitativo de salas aquém do necessário para suprir as demandas de todos. Além da insuficiência, foi revelado também o problema da inadequação dos espaços existentes, com salas pequenas para os atendimentos compartilhados e ausência de espaços para as atividades coletivas, como grupos de educação em saúde ou terapêuticos.

Nenhuma estrutura, né? Você tá percebendo agora que não tem, né? Você acaba sendo o resto, a equipe resto. O que restar para você de sala você usa. Não tem estrutura física nem pra eles mesmos da equipe, às vezes. Falta até essa estrutura. Então, pra gente do NASF muito menos (NASF 42, Fisioterapeuta).

A gente disponibiliza a recepção da sala odontológica, uma sala de procedimento onde o fisioterapeuta fica pra utilizar já a maca. Então, a gente sai improvisando uma sala pra que eles possam realizar suas consultas (eSFs 26, Enfermeiro).

Os arranjos para superação das carências de espaço é a utilização dos consultórios destinados aos médicos e enfermeiros, quando esses profissionais não se encontram na USF, além do uso de outros espaços com a farmácia, copa, entre outros. A insuficiência e inadequação das USFs geram transtornos e dificuldades no desenvolvimento das ações do NASF. Em determinadas situações desencadeiam no cancelamento das atividades programadas por limitações do espaço físico.

Já deixei de realizar atividade por não ter espaço. Tudo cheio os espaços, né? E aí não tinha o local, não tinha como a gente realizar a atividade. A gente teve que esperar todo mundo da unidade. (...) Só que quando isso acontece, a gente perde o crédito com a população, né? (NASF 05, Fisioterapeuta).

Além dos ambientes internos da USF, os profissionais encontram dificuldades de uso dos espaços no território. Espaços nas comunidades, a exemplo de igrejas, creches, garagens e associações, são buscados com frequência. Todavia, foram também evidenciadas dificuldades de uso desses ambientes, tanto por inapropriação como por dificuldades de agendamento. Além de que, em algumas comunidades, especialmente nas mais carentes, são escassos ou inexistentes os equipamentos comunitários. Nesse sentido, os profissionais buscam realizar as adaptações necessárias ou fazem uso de espaços não convencionais para o desenvolvimento do seu trabalho.

Utilizar igreja, até em porta de bar. Eu já fiz grupo dentro de um bar. Então, assim, você tem que aproveitar o que você tem, que no caso da gente é muito pouca coisa (NASF 36, Fisioterapeuta). 
Dificuldades relativas ao espaço físico são vivenciadas em diversas localidades. Gonçalves et al. (2015) identificaram ausência e inadequação dos espaços físicos tanto nas unidades de saúde quanto no território, o que compromete a realização dos atendimentos individuais e das atividades em grupo. Em Minas Gerais foram evidenciadas limitações no desenvolvimento de práticas corporais e de educação física no NASF devido à infraestrutura inadequada (Saporetti, Miranda e Belisário, 2016).

Cabe destacar que o uso dos espaços no território é um dos preceitos do trabalho dos núcleos de apoio (Brasil, 2012; Brasil, 2014), com potencialidade de ampliar a capacidade de intervenção coletiva, favorecer o vínculo e possibilitar melhor conhecimento da realidade do território, dentre outras vantagens. No entanto, a estratégia de acionar espaços na comunidade não substitui a necessidade de adequada estrutura física nas USFs. Para o desenvolvimento do trabalho de apoio matricial é necessário que as unidades disponham de estrutura mínima necessária à realização das atividades, sejam elas individuais, compartilhadas ou grupais.

O estudo evidenciou também dificuldades na disponibilidade de transporte para as equipes de apoio. Embora os municípios se proponham a assegurar veículos para que os trabalhadores se desloquem nas áreas de atuação, no cotidiano do trabalho os profissionais encontram dificuldades para fazer uso desse aparato. Foi possível perceber que ter um carro disponibilizado para o NASF não significava, necessariamente, a possibilidade de uso.

Mas assim, tem carro? Agora tem, dessa maneira, né? Mas, temos muita dificuldade de acesso, sabe? É porque é assim, tem que ficar ligando, tem que correr na frente porque se não pode perder o carro, o carro já ter desviado pra outro local, entendeu? (NASF 27, Nutricionista).

Muitas vezes, os veículos, mesmo disponíveis, são sempre compartilhados, seja entre as equipes de NASF e eSF, seja por outros setores e necessidades das secretarias de saúde. Os veículos que, em tese, eram disponibilizados para o trabalho dos profissionais no território, por vezes eram deslocados para atender outras demandas, dificultando as ações da equipe de apoio, quando essas necessitavam de transporte.

E aí, às vezes, a gente já deixou de fazer atendimento porque o carro não tava disponível. Teve que viajar, pra levar paciente, pra fazer tratamento de quimio. A gente já teve que desmarcar visita (NASF 29, Fisioterapeuta). 
Então, logo, tem um veículo para 22 profissionais. É um veículo para todo o NASF. São quatro núcleos, aí a gente tem 22 profissionais. Então, pra mim fica inviável. Eu particularmente não uso o veículo do NASF (NASF 35, Prof. Educação Física).

A dificuldade de transporte para os profissionais de apoio também foi observada na cidade de São Paulo. Gonçalves et al. (2015) verificaram a escassez de transporte oficial para que o NASF se deslocasse e realizasse as atividades na diversidade de equipamentos de saúde e sociais, que são seu campo de prática. Lancman et al. (2013) referiram dificuldades de deslocamento dos profissionais do NASF para a realização das atividades previstas e uso de meio de transporte próprio para fazer a locomoção nas comunidades.

No cenário do estudo, para que as ações e demandas não ficassem inviabilizadas, muitos trabalhadores optaram por disponibilizar fazer uso do o próprio veículo, ir a pé ou fazer uso de outros artifícios para se deslocar no desenvolvimento do trabalho.

Eu falava assim, que pra mim, melhorou agora porque eu comprei uma motinha, que aí eu vou para todos os cantos (NASF 27, Nutricionista).

Um carro só, e somente para a zona rural. Para a zona urbana não tem, né? Aí, cada um vai se virar para poder ir, ou a pé ou de mototáxi ou quem tem carro vai de carro (NASF 16, Fisioterapeuta).

Nesse contexto, foram evidenciadas dificuldades para realização de algumas atividades e até mesmo cancelamento de outras por conta da ausência de veículo. Percebeu-se que muitos profissionais agendam um menor número de atividades e, consequentemente, não otimizam o tempo de trabalho por causa de problemas no acesso ao transporte.

Assim, a gente acaba marcando menos atividades por conta da ausência de transporte, né? (...) Assim, às vezes faz zona rural, não tem carro pra poder fazer visita com a gente lá. Então, a gente deixa de fazer algumas atividades (NASF 15, Farmacêutico).

Araújo e Galimbertti (2013) apontam que a dificuldade em relação ao transporte para as equipes de matriciamento torna delicada a tarefa de operacionalização do trabalho, uma vez que inviabiliza o suporte necessário para os processos de produção do cuidado e promoção da saúde, o que gera, inclusive, conflitos e sofrimento.

Em relação à disponibilidade de materiais e equipamentos para o trabalho do NASF, observou-se existir dificuldades na viabilização desses insumos. Embora alguns itens sejam ofertados, os profissionais não dispõem dos 
instrumentos básicos necessários ao desenvolvimento do trabalho. Tanto se evidenciou escassez de materiais para as ações educativas e de uso nos grupos de saúde, como também ausência de equipamentos destinados aos atendimentos individuais.

Muita dificuldade em relação a material. Nós temos quatro anos de existência. E desde que o NASF foi implantado, nós solicitamos uma lista de material e até hoje o material não chegou (NASF 02, Nutricionista).

As dificuldades com instrumentos e recursos acabam por interferir no resultado do trabalho dos profissionais e muitas atividades não são realizadas ou têm um resultado abaixo do esperado por conta dessas limitações. Observou-se uma convergência em torno da necessidade de materiais de apoio para a realização de atividades mais dinâmicas e atrativas para a população.

Que a gente sabe que, por exemplo, pra gente desenvolver uma atividade em grupo com a comunidade é, quando você vai lá só falar, falar, falar, falar, você não tem uma efetividade realmente das ações. A gente precisa de material, de outras formas que a gente possa desenvolver com a comunidade (NASF 41, Farmacêutico).

Dificuldades estruturais e de recursos materiais são sentidas não só pelos apoiadores, mas também entre as eSFs. Estudos avaliativos sobre a saúde da família (Serapioni e Silva, 2011; Trad e Rocha, 2011; Bertoncini, Pires e Scherer, 2011) destacam as dificuldades de se trabalhar numa estrutura não adequada às necessidades do serviço e nem sempre dotadas dos equipamentos minimamente necessários, o que traz prejuízos para os usuários. Também em outros países, a questão estrutural mostra-se como fator interveniente na qualidade do cuidado prestado na APS (Schadewaldt, et al. 2016). Na África do Sul foi observada falta de equipamentos necessários para o acompanhamento de portadores de doenças crônicas (Ameh et al., 2016). Na Colômbia, Mosquera et al. (2013) concluem que as questões estruturais são requisitos essênciais para implementação de uma estratégia abrangente e bem-sucedida de APS.

Diante das carências identificadas, muito profissionais lançam mão do improviso ou optam por materiais próprios ou emprestados para viabilizar a realização de atividades.

Se a gente quiser fazer uma coisa mais elaborada, tudo tem que sair do nosso bolso. Porque a gente não tem apoio de nada assim, de materiais. Muitas vezes... Muitas vezes não, nunca. Falta sempre, né? (NASF 38, Nutricionista). 
Martinez, Silva e Silva (2016) reportam que a implantação dos NASF no país enfrenta dificuldades no que concerne à estrutura física das unidades de saúde, transporte e materiais, principalmente aquelas que se referem às atividades de educação em saúde. Os autores afirmam que esta condição de precariedade não é rara no âmbito da ESF e tende a se intensificar com a implantação de equipes de apoio.

Nessa categoria, tomando-se por referência o matriciamento como eixo central de análise, evidenciam-se dificuldades nas dimensões institucional e terapêutica. O fazer do NASF além de se fundamentar numa metodologia inovadora da organização do trabalho, também pressupõe a necessidade de condições estruturais mínimas. Assim, o desenvolvimento do apoio matricial implica comprometimento e garantias institucionais por parte da gestão em assegurar a infraestrutura necessária.

Os achados do estudo também demonstram a forte vinculação da dimensão institucional com a dimensão terapêutica, em que as fragilidades das condições estruturais desencadeiam restrições das atividades desenvolvidas pelos profissionais, sejam elas individuais ou coletivas. Nesse sentido, a efetividade do trabalho do NASF e a possibilidade de ampliação da resolutividade na APS são abaladas frente às limitações organizacionais e estruturais. Importante refletir que o matriciamento não se viabiliza apenas com a incorporação de profissionais de outras especialidades se não houver direção e apoio da gestão.

\section{Valorização e gestão do trabalho}

Emergiram alguns fatores relacionados à baixa valorização do trabalho dos profissionais de apoio, com destaque para a diminuta adesão da comunidade às ações coletivas, a insatisfatória remuneração e a sobrecarga de trabalho. No que se refere à população, foi destacada a excessiva valorização do atendimento médico prescritivo, em que as pessoas apreciam mais a terapia medicamentosa em detrimento de ações voltadas para o trabalho educativo, em grupo, focado na prevenção e promoção da saúde.

Eu acho que é a compreensão também da população em relação ao nosso trabalho. Só mesmo de mudar essa cultura de achar que é só consulta médica, só a medicação resolve, né? A maior dificuldade, hoje, acredito que em todo o NASF, é de sensibilizar as pessoas, né? Essa questão cultural é complicada (NASF 04, Fisioterapeuta).

Hori e Nascimento (2014) relatam a falta de adesão das comunidades às atividades em grupo desenvolvidas pelo NASF, o que leva mesmo à descontinuidade de muitas atividades. Ressaltam ainda que este aspecto gera descontentamento e sentimento de desvalorização para os profissionais. Patrocínio, Machado e Fausto (2015) afirmam que o conhecimento e a adesão da 
comunidade às ações coletivas são desafios impostos para a concretização da proposta em municípios do Rio de Janeiro. Para Trindade e Pires (2013), as mudanças das práticas do modelo biomédico para aquelas que focam a promoção e a educação em saúde, como principal estratégia do trabalho, ainda se fazem tímidas. Transformações das práticas tradicionais exigem um esforço contínuo e conjunto, em que os profissionais que atuam na APS sejam capazes de desenvolver uma clínica centrada no sujeito, para que, de forma gradual, isto seja incorporado culturalmente pela sociedade.

As questões relacionadas à gestão do trabalho, especialmente a baixa remuneração e a precarização de vínculos, foram apresentadas como percalços que interferem negativamente no desempenho das equipes de apoio. A maior parte dos profissionais entrevistados possui contratos temporários de trabalho, muitos deles por indicação política, e salários abaixo de suas expectativas.

Se melhorasse a questão salarial acho que, também, o pessoal melhoraria também. Até mesmo a vontade de querer se doar mais, se dedicar mais. Porque aqui o problema é: se você é contratado você recebe xis, se você é concursado pra fazer a mesma coisa você recebe dois xis (NASF 27, Nutricionista).

Outros estudos demostram prevalecer formas precárias de contratação e vínculo dos trabalhadores do NASF (Patrocínio, Machado e Fausto, 2015), embora também se observem situações de vinculação por concurso público e salários atrativos, como observado em Goiânia (Martinez, Silva e Silva, 2016). Os vínculos de trabalho e as questões salariais têm se mostrado um desafio para o cotidiano de trabalho da APS. Conforme destacam Mendonça e colaboradores (2010), a precarização do trabalho em saúde interfere diretamente na qualidade das ações desenvolvidas. Assim, os vínculos estáveis de trabalho e a valorização salarial resultam em impacto positivo na fixação profissional, na educação permanente e no melhor desempenho nas ações de saúde.

Também a elevada demanda e o número excessivo de eSFs por NASF foram apontados como dificultadores do trabalho. Em decorrência da quantidade elevada de eSFs apoiadas, os núcleos acabam por não conseguir se fazer frequente e atuante em todas as equipes e territórios.

O número de equipes que é apoiada por cada NASF eu acho que tinha que ser reduzido. Pra que eles ficassem mais tempo com as equipes, entendeu? Pra que eles pudessem vir nas reuniões da gente, né? Pra que eles estivessem na reunião do Conselho de Saúde, a gente nunca tem o NASF na reunião do Conselho de Saúde (eSF 33, Enfermeiro).

O número excessivo de eSFs a serem matriciadas gera dificuldades no acompanhamento, tornando a construção das agendas desafiadora e desgas- 
tante (Araújo e Galimbertti, 2013). Em estudo realizado em Guarulhos (Hori e Nascimento, 2014) também se observou grande quantidade de eSFs por NASF com uma presença não sistemática deste nas USFs, o que resulta em fragilidade no vínculo entre equipe de apoio e equipe de referência.

O Ministério da Saúde (Brasil, 2012) estabelece um limite máximo de nove eSFs apoiadas por núcleo. Não obstante já ser este um quantitativo elevado, como agravante observa-se que muitas eSFs atuam com um número de pessoas muito além do preconizado (Trad e Rocha, 2011). Assim, o NASF, por consequência, vivencia também essa discrepância entre a demanda recomendada para o seu trabalho e as realidades dos territórios.

Diante dos achados relativos à valorização e à gestão do trabalho, também se demonstram implicações nas dimensões organizacionais e terapêuticas sobre o trabalho das equipes de apoio. Questões relacionadas à remuneração salarial, aos vínculos trabalhistas e à sobrecarga de trabalho são responsabilidades institucionais que precisam ser enfrentadas a fim de superar os mecanismos de precarização das relações e condições de trabalho ainda vigentes no SUS. Além do mais, tais situações interferem na dimensão terapêutica, com limitação do fazer cotidiano dos profissionais e consequente comprometimento da qualidade da assistência prestada aos usuários.

\section{Considerações finais}

Os achados da pesquisa evidenciaram que a proposta do NASF ainda enfrenta dificuldades e desafios para que se concretize como objeto de transformação das práticas de saúde. Foram evidenciadas compreensão dual sobre o trabalho do NASF e sua forma de atuação. Questões referentes à infraestrutura, à valorização profissional e à gestão do trabalho também foram apontadas como obstáculos para a efetivação do apoio matricial. As características mais relevantes do estudo refletem a necessidade de maior proximidade na organização do trabalho entre equipes de referência e de apoio, bem como a revisão das questões estruturais e da valorização profissional. Estas barreiras indicam dificuldades de ação com base nas prerrogativas do apoio matricial.

Iniciativas que objetivem superar tais dificuldades devem ser viabilizadas. Para tanto, sugere-se o fortalecimento dos mecanismos da educação permanente em saúde, de forma a contemplar a metodologia do apoio matricial. Também é necessário maior sensibilização e comprometimento dos gestores em direção à superação dos problemas estruturais e organizacionais encontrados na prática cotidiana da APS. Por fim, reflete-se que as incompreensões ao caráter inovador do Apoio matricial e as dificuldades estruturais não são indicativos da inefetividade do NASF, pelo contrário, apontam desafios ainda persistentes que necessitam ser superados em direção a uma APS abrangente e resolutiva. 


\section{Colaboradores}

José Patrício Bispo Júnior participou da concepção do estudo, coleta e análise de dados, redação do artigo e aprovação da versão final. Diane Costa Moreira participou da coleta e análise de dados, redação do artigo e aprovação da versão final.

\section{Financiamento}

A realização do estudo contou com apoio financeiro do Programa de Pesquisa para o SUS (PPSUS). Edital da Fundação de Amparo à Pesquisa do Estado da Bahia (FAPESB) n. 20/2013.

Resumen Este estudio teve como meta analizar el sentido atribuido al trabajo de los Núcleos de Apoyo a la Salud de la Familia, así como analizar los obstáculos y desafíos para la práctica cotidiana del apoyo matricial. Es un estudio cualitativo del tipo casos múltiples desarrollado en seis municipios de Bahía, Brasil. Se realizaron entrevistas semiestructuradas a 43 profesionales de los núcleos de apoyo y 40 de los equipos de salud de la familia. Se utilizó el referencial teórico del apoyo matricial en las dimensiones pedagógica, terapéutica e institucional. Los resultados se agruparon en tres categorias: (in)comprensión del trabajo de los núcleos de apoyo; infraestructura y condiciones de trabajo; valorización y gestión del trabajo. El estudio identificó diferentes comprensiones sobre el apoyo matrilcial entre profesionales de los núcleos de apoyo y de los equipos de salud de la família, con expectativas conflictivas e implicaciones para el trabajo. La infraestructura es insuficiente e inadecuada para el trabajo. La baja valorización de los núcleos de apoyo también se mostró com la pequeña adhesión de la comunidad a las actividades colectivas, la remuneración insatisfactoria y la sobrecarga de trabajo. Incomprensiones sobre el carácter innovador del matriciamiento y dificultades estructurales apuntan desafíos aún persistentes para la concreción de la función de apoyo Palabras clave atención primaria de la salud; salud de la família; grupo de atención al paciente; personal de salud.

\section{Notas}

${ }^{1}$ Universidade Federal da Bahia, Instituto Multidisciplinar em Saúde, Vitória da Conquista, Bahia, Brasil.

<jpatricio@ufba.br>

Correspondência: Universidade Federal da Bahia, Instituto Multidisciplinar em Saúde, Campus Anísio Teixeira, Rua Rio de Contas, 58, Candeias, CEP 45029-094, Vitória da Conquista, Bahia, Brasil.

${ }^{2}$ Universidade Federal da Bahia, Instituto Multidisciplinar em Saúde, Vitória da Conquista, Bahia, Brasil.

$<$ dicmoreira@hotmail.com> 


\section{Referências}

ABIIRO, Gilbert A.; DE ALLEGRI, Manuela. Universal health coverage from multiple perspectives: a synthesis of conceptual literature and global debates. BMC International Health and Human Rights, London, v. 15, n. 17, 2015.

AMEH, Soter et al. Quality of integrated chronic disease care in rural South Africa: user and provider perspectives. Health Policy and Plannning, London, v. 32, n. 2, p. 257-266, 2017.

ANJOS, Karla F. et al. Perspectivas e desafios do núcleo de apoio à saúde da família quanto às práticas em saúde. Saúde em Debate, Rio de Janeiro, v. 37, n. 99, p. 672-680, 2013.

ARAÚJO, Eliezer M. D.; GALIMBERTTI, Percy A. A colaboração interprofissional na estratégia saúde da família. Psicologia \& Sociedade, Belo Horizonte, v. 25, n. 2, p. 461-468, 2013.

BARROS, Juliana O. et al. Estratégia do apoio matricial: a experiência de duas equipes do Núcleo de Apoio à Saúde da Família (NASF) da cidade de São Paulo, Brasil. Ciência \& Saúde Coletiva, Rio de Janeiro, v. 20, n. 9, p. 2847-2856, 2015.

BERTONCINI, Judite H.; PIRES, Denise E. P.; SCHERER, Magda D. A. Condições de trabalho e renormalizações nas atividades das enfermeiras na Saúde da Família. Trabalho, Educação e Saúde, Rio de Janeiro, v. 9, supl.1, p. S157-173, 2011.

BRASIL. Politica Nacional de Atenção Básica. Brasília: Ministério da Saúde, 2012.

BRASIL. Núcleo de Apoio à Saúde da Família. Brasília: Ministério da Saúde, 2014. (Cadernos da Atenção Básica, 39).

BRASIL. Instituto Brasileiro de Geografia e Estatística. IBGE Cidades. Disponível em: $<$ http://www.cidades.ibge.gov.br/xtras/ uf.php?lang $=$ \& coduf $=29 \&$ search $=$ bahia $>$. Acesso em 22 de nov. de 2016.
CAMPOS, Gastão W. S. et al. A aplicação da metodologia Paideia no apoio institucional, no apoio matricial e na clínica ampliada. Interface: Comunicação, Saúde, Educação, Botucatu, v. 18, n.1, supl., p. S983-995, 2014.

CUNHA, Gustavo T.; CAMPOS, Gastão W. S. Apoio matricial e Atenção Primária em Saúde. Saúde e Sociedade, São Paulo, v. 20, n. 4, p. 961-970, 2011.

D'AMOUR, Danielle et al. A model and typology of collaboration between professionals in healthcare organizations. BMC Health Services Research, London, v. 8, n. 188, 2008.

GIBBS, G. Análise de Dados Qualitativos. Porto Alegre: Artmed, 2009.

GIOVANELLA, Ligia; MENDONÇA, Maria H. M. Atenção Primária à Saúde. In: GIOVANELLA, Ligia et al. (orgs.). Politicas e Sistemas de Saúde no Brasil. 2. ed. Rio de Janeiro: Editora Fiocruz, Cebes, 2012. p. 493-546.

GONÇALVES, Rita M. A. et al. Estudo do trabalho em Núcleos de Apoio à Saúde da Família (NASF), São Paulo, Brasil. Revista Brasileira de Saúde Ocupacional, São Paulo, v. 40, n. 131, p. 59-74, 2015.

HORI, Alice A.; NASCIMENTO, Andréia F. O Projeto Terapêutico Singular e as práticas de saúde mental nos Núcleos de Apoio à Saúde da Família (NASF) em Guarulhos (SP), Brasil. Ciência \& Saúde Coletiva, Rio de Janeiro, v. 19, n. 8, p. 3561-3571, 2014.

LANCMAN, Selma et al. Estudo do trabalho e do trabalhar no Núcleo de Apoio à Saúde da Família. Revista de Saúde Pública, São Paulo, v. 47, n. 5, p. 968-975, 2013.

MARTINEZ, Jéssica F. N.; SILVA, Maria S.; SILVA, Ana M. O Núcleo de Apoio à Saúde da Família em Goiânia (GO): percepções dos profissionais e gestores. Saúde em Debate, Rio de Janeiro, v. 40, n. 110, p. 95-106, 2016.

MENDONÇA, Maria H. M. et al. Desafios para gestão do trabalho a partir de experiências 
exitosas de expansão da Estratégia de Saúde da Família. Ciência \& Saúde Coletiva, Rio de Janeiro, v. 15, n. 5, p. 2355-2365, 2010.

MOSQUERA, Paola A. et al. Performance evaluation of the essential dimensions of the primary health care services in six localities of Bogota-Colombia: a cross-sectional study. BMC Health Services Research, London, v. 13, p. 315, 2013.

OLIVEIRA, Mônica M.; CAMPOS, GastãoW. S. Apoios matricial e institucional: analisando suas construções. Ciência \& Saúde Coletiva, Rio de Janeiro, v. 20, n. 1, p. 229-238, 2015.

PATROCÍNIO, Shirley S. M.; MACHADO, Cristiane V.; FAUSTO, Márcia C. R. Núcleo de Apoio à Saúde da Família: proposta nacional e implementação em municípios do Rio de Janeiro. Saúde em Debate, Rio de Janeiro, v. 39, n. esp., p. 105-119, 2015.

RIBEIRO, Cristina D.; FLORES-SOARES, Maria C. Desafios para a inserção do fisioterapeuta na atenção básica: o olhar dos gestores. Revista de Salud Pública, Bogotá, v. 17, n. 3, p. 379-393, 2015.

SAPORETTI, Gisele M.; MIRANDA, Paulo S. C.; BELISÁRIO, Soraya A. O profissional de educação física e a promoção da saúde em núcleos de apoio à saúde da família. Trabalho, Educação e Saúde, Rio de Janeiro, v. 14, n. 2, p. 523-543, 2016.

SCHADEWALDT, Verena et al. Experiences of nurse practitioners and medical practitioners working in collaborative practice models in primary healthcare in Australia - a multiple case study using mixed methods. BMC Family Practice, London, v. 17, p. 99, 2016.
SERAPIONI, Mauro; SILVA, Marcelo G. C. Avaliação da qualidade do programa Saúde da Família em municípios do Ceará: uma abordagem multidimensional. Ciência \& Saúde Coletiva, Rio de Janeiro, v. 16, n. 11, p. 4315-4326, 2011.

SOUSA, Diogo; OLIVEIRA, Isabel F.; COSTA, Ana L. F. Entre o especialismo e o apoio: psicólogos no Núcleo de Apoio à Saúde da Família. Psicologia USP, São Paulo, v. 26, n. 3, p. 474-483, 2015.

SOUZA, Marize B. et al. Trabalho em equipe na atenção primária: a experiência de Portugal. Revista Panamericana de Salud Publica, Washington, D.C., v. 33, n. 3, p. 190-195, 2013.

STARFIELD, Barbara. Primary care: an increasingly important contributor to effectiveness, equity, and efficiency of health services. SESPAS report 2012. Gaceta Sanitaria, Barcelona, v. 26, Suppl. 1, p. S20-26, 2012.

TRAD, Leny A. B.; ROCHA, Ana A. R. M. Condições e processo de trabalho no cotidiano do Programa Saúde da Família: coerência com princípios da humanização em saúde. Ciência \& Saúde Coletiva, Rio de Janeiro, v. 16, n.3, p. 1969-1980, 2011.

TRINDADE, Letícia L.; PIRES, Denise E. P. Implicações dos modelos assistenciais da atenção básica nas cargas de trabalho dos profissionais de saúde. Texto \& Contexto: Enfermagem, Florianópolis, v. 22, n. 1, p. 36-42, 2013.

YIN, Robert K. Estudo de caso: planejamento e métodos. 4. ed. Porto Alegre: Bookman, 2010.

Recebido em 21/02/2017.

Aprovado em 19/06/2017.

\section{Errata}

Na página 700, artigo “NÚCLEOS DE APOIO À SAÚDE DA FAMÍLIA: CONCEPÇÕES, IMPLICAÇÕES E DESAFIOS PARA O APOIO MATRICIAL", autoria de José Patrício Bispo Júnior e Diane Costa Moreira, com o DOI: 10.1590/1981-7746-sol00122, publicado no periódico Trabalho, Educação e Saúde, v. 16, n. 2, p. 683-702, incluiram-se os dados sobre o financiamento da pesquisa, em que se lê:

\section{Financiamento}

A realização do estudo contou com apoio financeiro do Programa de Pesquisa para o SUS (PPSUS). Edital da Fundação de Amparo à Pesquisa do Estado da Bahia (FAPESB) n. 20/2013. 